\title{
COMPOSIÇÃO QUÍMICA E ATIVIDADE ANTIMICROBIANA DAS FOLHAS DA ESPÉCIE Vatairea macrocarpa (BENTH) DUCKE
}

\author{
Byanka Silva Sena $^{1}$; Angélica Maria Lucchese' ${ }^{2}$ Jade Ribeiro Carneiro $^{3}$
}

1. Bolsista PIBIC/CNPq, Graduando em Farmácia, Universidade Estadual de Feira de Santana, e-mail: byankasena8@gmail.com

2. Orientador, Departamento de Exatas, Universidade Estadual de Feira de Santana, e-mail: angelica.lucchese@gmail.com

3. Participante do projeto, Departamento de Ciências Biológicas, Universidade Estadual de Feira de Santana, e-mail: rc.jade@hotmail.com

PALAVRAS-CHAVE: Cromatografia; Atividade antimicrobiana; Fracionamento.

\section{INTRODUÇÃO}

O gênero Vatairea é nativo do Brasil, porém pode ser encontrado em outras regiões como Guiana e regiões litorais atlânticas da América Central e do México. No Brasil as espécies do gênero Vatairea estão presentes nas regiões dos domínios fitogeográficos da Amazônia, Cerrado e Mata Atlântica, podendo ser encontradas neste país sete espécies desse gênero (Cardoso, 2012). A espécie Vatairea macrocarpa (Benth.) Ducke é típica do cerrado, campo cerrado e cerradões do Brasil, sendo conhecida popularmente como maleiteira, angelim-do-cerrado e como amargoso, devido ao chá da casca do caule ser amargo (Oliveira et al, 2008).

A resistência a drogas de patógenos humanos e animais é um dos casos mais bem documentados de evolução biológica e um sério problema tanto em países desenvolvidos como em desenvolvimento. A pesquisa de novos agentes antimicrobianos se faz necessária devido ao surgimento de microrganismos resistentes e de infecções oportunistas fatais, associadas a AIDS, quimioterapia antineoplásica e transplantes (Penna et al., 2001).

Em estudos anteriores do presente grupo de pesquisa, o extrato metanólico da espécie $V$. macrocarpa foi capaz de inibir o crescimento de Staphylococcus aureus com CIM de $350 \mu \mathrm{g} . \mathrm{mL}^{-1}$, Candida albicans com CIM de $600 \mu \mathrm{g} . \mathrm{mL}^{-1}$ e Candida parapsilosis com CIM de $170 \mu \mathrm{g} . \mathrm{mL}^{-1}$ apresentando um grande potencial como produto na busca de antimicrobianos (Valadares, 2014). Desta forma objetivou-se, com este trabalho, continuar as pesquisas com a espécie, prosseguindo com fracionamento e análise das frações mais ativas.

\section{METODOLOGIA}

\section{Preparação das frações}

Para a preparação das frações, o extrato bruto de Vatairea macrocarpa foi ressuspenso em metanol/água (8:2) e extraído sucessivamente com hexano, diclorometano, acetato de etila e butanol. Após as extrações, o solvente das frações foi removido em evaporador rotatório, sob pressão reduzida. O resíduo de solvente foi retirado por evaporação em capela de exaustão. A fase aquosa resultante foi armazenada em freezer para posterior liofilização.

\section{Determinação da atividade antimicrobiana}


Foi utilizada a metodologia de determinação da Concentração Inibitória Mínima (CIM) descrita no Clinical and Laboratory Standards Institute - CLSI (2002), para leveduras, e no CLSI (2003), para as bactérias. Os microrganismos testados foram: Staphylococcus aureus (CCMB 262) resistente à Estreptomicina e Dihidrostreptomicina; Candida albicans (CCMB 286) resistente à Fluconazol e Anfotericina B. A determinação da CIM dos extratos metanólicos foi realizada em placas estéreis de poliestireno, com 96 poços, através de microdiluição e as concentrações variaram de $9,9 \mathrm{mg} / \mathrm{mL}$ a 0,0048 $\mathrm{mg} / \mathrm{mL}$ nos poços.

No teste CMM foram retirados $5 \mu \mathrm{L}$ de cada poço das placas de CIM em que houve inibição do crescimento microbiano, e transferidos para uma placa de Petri com meio ágar Müeller Hinton. O conteúdo de cada poço foi colocado em quadrantes específicos da placa de Petri, identificados com o número e a letra do poço a ser testado, o microorganismo teste e o código da amostra. As placas com as bactérias foram incubadas por $24 \mathrm{~h}$ a $37^{\circ} \mathrm{C}$ e as placas com leveduras por $48 \mathrm{~h}$ a $28^{\circ} \mathrm{C}$. Depois desse período, a Concentração Microbicida Mínima foi a menor concentração da amostra onde não ocorreu crescimento microbiano.

\section{Determinação do perfil cromatográfico por cromatografia em camada delgada}

O perfil cromatográfico por cromatografia em camada delgada foi determinado com $o$ emprego de reveladores químicos para a detecção das classes de metabólitos, como terpenos e esteroides, flavonoides, cumarinas, triterpenos, entre outros, conforme Wagner e Bladt (1995).

\section{RESULTADOS E/OU DISCUSSÃO}

\section{Preparo das frações:}

Após a ressuspensão do extrato bruto das folhas de Vatairea macrocarpa em metanol/água, e extração sucessiva com hexano, diclorometano, acetato de etila e butanol foram obtidas as respectivas frações com os seguintes teores de extrativos: fração em hexano - 10,14\%, fração em diclorometano - 8,79\%, fração em acetato de etila $-17,75 \%$ e fração em butanol - 53,29\%.

\section{Cromatografia em camada delgada:}

Para a eluição das amostras foi utilizado dois tipos de sistemas de misturas, um para frações apolares e outro para polares, para frações polares foi utilizada a mistura acetato de etila e clorofórmio (25:6), enquanto que para apolares foi utilizado o sistema tolueno e acetato de etila (8:2). O teste para detecção de terpenos se mostrou positivo em todas as frações analisadas. A revelação com o reagente Liebermand-Buchard mostrou teste positivo para a presença de triterpenos e esteroides, em todas as frações. Com o revelador NP/PEG, observou-se a presença de compostos flavonoides em todas as frações presentes, como pode ser observado na figura 1 para as frações em acetato de etila e butanol. Pode se observar que o reagente $\mathrm{KOH}$ para detecção de antraquinonas se mostrou negativo quando observado à luz UV. Para o teste de detecção de alcalóides, as amostras também obtiveram resultado negativo para o reagente Dragendorff. Diante dessas informações observa-se que as frações contêm uma variedade de compostos metabólitos secundários, como terpenos, esteroides e flavonoides, que poderão ser responsáveis pelas atividades das mesmas. 


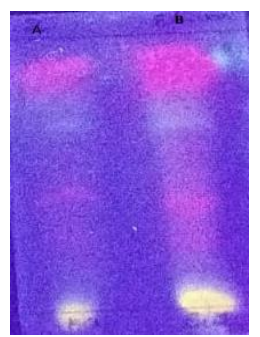

Figura 1: Cromatografia em camada delgada com revelador NP para compostos fenólicos, A - fração em acetato de etila e B fração em butanol.

\section{Atividade antimicrobiana:}

Os testes de determinação da Concentração Inibitória Mínima (CIM) e de Concentração microbicida mínima (CMM) foram realizados para todas as frações e o resultados estão apresentados na Tabela 1.

Tabela 1 - Atividade antimicrobiana das frações em hexano, diclorometano, acetato de etila e butanol.

\begin{tabular}{|c|c|c|c|c|}
\hline \multirow[t]{2}{*}{ Fração } & \multicolumn{2}{|c|}{ C. albicans } & \multicolumn{2}{|c|}{ S. aureus } \\
\hline & $\operatorname{CIM}(\mu \mathrm{g} / \mathrm{mL})$ & CMM $(\mu \mathrm{g} / \mathrm{mL})$ & $\operatorname{CIM}(\mu \mathrm{g} / \mathrm{mL})$ & CMM( $(\mu \mathrm{g} / \mathrm{mL})$ \\
\hline Hexano & $\mathbf{R}$ & $\mathbf{R}$ & $\mathbf{R}$ & $\mathbf{R}$ \\
\hline Diclorometano & $51,99 \pm 12,92$ & $55,24 \pm 9,77$ & $25,78 \pm 9,7$ & $77,34 \pm 0$ \\
\hline Acetato de etila & $309,38 \pm 0$ & $309,38 \pm 0$ & $77,34 \pm 0$ & $223,44 \pm 29,77$ \\
\hline Butanol & $\mathbf{R}$ & $\mathbf{R}$ & $1737,5 \pm 0$ & $4125,00 \pm 1237,50$ \\
\hline Controle & $<10 \mu \mathrm{g} / \mathrm{mL}$ & NT & $<10 \mu \mathrm{g} / \mathrm{mL}$ & NT \\
\hline
\end{tabular}

NT = Não testada R = Resistente até a maior concentração testada $(9,9 \mathrm{mg} / \mathrm{mL})$ Controles: Nistatina para C. albicans e Cloranfenicol para S. aureus.

Diante dos dados dessa tabela pode-se observar que a fração que apresentou um melhor resultado para o teste de concentração inibitória mínima foi a fração em diclorometano, apresentando uma menor concentração necessária de $25,78 \mu \mathrm{g} / \mathrm{mL}$, para a inibição do crescimento de Staphylococcus aureus e de 52,00 $\mu \mathrm{g} / \mathrm{ml}$ para inibir o crescimento de Candida albicans, assim esta se mostrou uma fração mais potente em testes in vitro para a inibição destes microrganismos. Com relação à concentração microbicida mínima, observou-se que esta fração apresenta uma ação bacteriostática no valor da concentração inibitória mínima, uma vez que os valores de CMM foram mais elevados que da CIM.

A fração em acetato de etila apresentou uma concentração inibitória mínima de 309,38 $\mu \mathrm{g} / \mathrm{ml}$ frente à Candida albicans, sendo esta também a sua concentração microbicida mínima. Já sua concentração inibitória mínima frente à Staphylococcus aureus foi de $77,34 \mu \mathrm{g} / \mathrm{mL}$, enquanto sua concentração microbicida mínima foi de $223,44 \mu \mathrm{g} / \mathrm{mL}$, portanto com ação bacteriostática até esta concentração.

A fração butanólica testada não foi capaz de inibir o crescimento de Candida albicans, portanto demonstrou ser resistente a esta fração, uma vez que até concentrações de $0,0048 \mu \mathrm{g} / \mathrm{mL}$ a fração não foi capaz de inibir seu crescimento, no entanto apresentou atividade quanto à Staphylococcus aureus, apesar das concentrações terem sido relativamente altas. Além disso, a fração hexânica não demonstrou atividade satisfatória frente à nenhum microorganismo, sendo resistente até as maiores concentrações avaliadas $(9,9 \mu \mathrm{g} / \mathrm{mL})$.

Os controles positivos para a realização dos testes foram o cloranfenicol para a $S$. aureus e a nistatina para a $C$. albicans, e apresentaram concentrações de atividade menores que $10 \mu \mathrm{g} / \mathrm{mL}$. A placa do teste de determinação da CIM para a fração em acetato de etila após revelação pode ser observada na figura 2: 


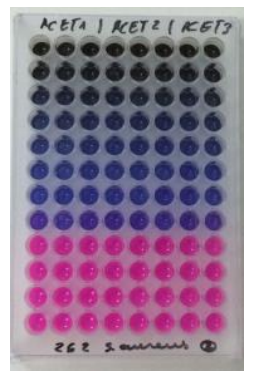

Figura 2: Resultado da determinação da CIM para a fração em acetato de etila frente à S. aureus.

\section{CONSIDERAÇÕES FINAIS}

Diante dos resultados obtidos conclui-se que a fração em diclorometano foi a que apresentou melhor atividade, o que indica que os componentes responsáveis pela atividade antimicrobiana em sua maioria, ou os de maior potência, estavam contidos nessa fração. Desta forma, sugere-se que, em trabalhos futuros, esta fração seja purificada para o isolamento dos metabólitos com ação antimicrobiana.

\section{REFERÊNCIAS}

CARDOSO, D. B. O. S. Vatairea in Lista de Espécies da Flora do Brasil. Jardim Botânico do Rio de Janeiro, 2012. Disponível em:

<http://floradobrasil.jbrj.gov.br/jabot/floradobrasil/FB23208>. Acesso em: 09 abr. 2014.

CLINICAL AND LABORATORY STANDARDS INSTITUTE (CLSI). 2002. Método de Referência para Testes de Diluição em Caldo para a Determinação da Sensibilidade a Terapia Antifúngica das Leveduras; Norma Aprovada - Segunda Edição. CLSI document M27-A2 [ISBN 1-56238-469-4]. CLSI, 940 West Valley Road, Suite 1400, Wayne, Pennsylvania 19087-1898 Estados Unidos.

CLINICAL AND LABORATORY STANDARDS INSTITUTE (CLSI). Methods for Dilution Antimicrobial Susceptibility Tests for Bacteria That Grow Aerobically; Approved Standard-Sixth Edition. CLSI document M7-A6 (ISBN 1-56238-486-4). CLSI, 940 West Valley Road, Suite 1400, Wayne, Pennsylvania 19087-1898 USA, 2003.

OLIVEIRA, H. C. Antidiabetic activity of Vatairea macrocarpa extract in rats. Journal of Ethnopharmacology. v. 115, p. 515-519, 2008.

PENNA, C. ; MARINO, S. ; VIVOT E. ; CRUAÑES M. C. ; MUÑOZ, J. D. ; CRUAÑES, J. ; FERRARO, G. ; GUTKIND, G. ; MARTINO. Antimicrobial activity of Argentine plants used in the treatment of infectious diseases. Isolation of active compounds from Sebastiania brasiliensis. J Ethnopharmacol, v.77, n.1, p. 37-40, 2001.

VALADARES, S. N. S. Composição Química e atividade antimicrobiana das folhas de Lueltzelburgia auriculata (allemao) Ducke e Vatairea macrocarpa (Benth) Ducke (Leguminosae). Feira de Santana, 2014. 57 p.

WAGNER, H.; BLADT, S. Plant Drug Analysis: a thin layer chromatography atlas. Berlin: Springer Verlag, 1995. 384p. 